\title{
Critical Hypersonic Aerothermodynamic Phenomena
}

\author{
John J. Bertin ${ }^{1,2}$ and Russell M. Cummings ${ }^{2}$ \\ ${ }^{1}$ Department of Mechanical Engineering and Materials Science, Rice University, Houston, Texas 77251; \\ email: jjbertin@rice.edu \\ ${ }^{2}$ Department of Aeronautics, U.S. Air Force Academy, U.S.A.F. Academy, Colorado 80840; \\ email: russ.cummings@usafa.edu
}

\section{Key Words}

hypersonic, ground testing, CFD, flight testing, boundary-layer transition

\begin{abstract}
The challenges in understanding hypersonic flight are discussed and critical hypersonic aerothermodynamics issues are reviewed. The ability of current analytical methods, numerical methods, ground testing capabilities, and flight testing approaches to predict hypersonic flow are evaluated. The areas where aerothermodynamic shortcomings restrict our ability to design and analyze hypersonic vehicles are discussed, and prospects for future capabilities are reviewed. Considerable work still needs to be done before our understanding of hypersonic flow will allow for the accurate prediction of vehicle flight characteristics throughout the flight envelope from launch to orbital insertion.
\end{abstract}




\section{INTRODUCTION}

"Aerothermodynamics couples the disciplines of aerodynamics and thermodynamics" (Gnoffo et al. 1999). The flow field for a vehicle that flies at hypersonic speeds is one in which high-temperature gas effects strongly influence the forces acting on the surface (the pressure and the skin friction) and the energy flux (the convective and the radiative heating). Hypersonic flows are usually characterized by the presence of strong shocks and equilibrium or nonequilibrium gas chemistry. Accurate prediction of these effects is critical to the design of any vehicle that flies at hypersonic velocities. The pressures and skin friction forces acting on the surface of the vehicles are integrated over the complete configuration to define the aerodynamic forces and moments (e.g., lift, drag, pitching moment, and control surface effectiveness). The peak heat-transfer rate and the heating load, which is the heating rate integrated over time, are mapped over the vehicle surface as part of the process to design the thermal protection system (TPS). Pressure distributions are required for assessing structural loads and venting environments.

To reduce the cost or to improve the reliability of hypersonic vehicles, programs must seek to apply advancements in technology and/or in processes. Incremental changes can produce evolutionary progress. Thus, technology relating to nonintrusive diagnostics whose fundamental principles and method of application are well known can be applied to slightly different applications to improve reliability and reduce recurring costs. This is indicated by the upper right-hand quadrant of the notional presentation of Knowledge Management Space (Figure 1), which was developed by L. Matsch \& J. McMasters (personal communication). Such evolutionary progress can be accomplished readily by the companies that design and produce hypersonic systems. The upper left-hand quadrant of Figure 1 addresses capabilities of which we are aware but do not know how to design or to build a system that

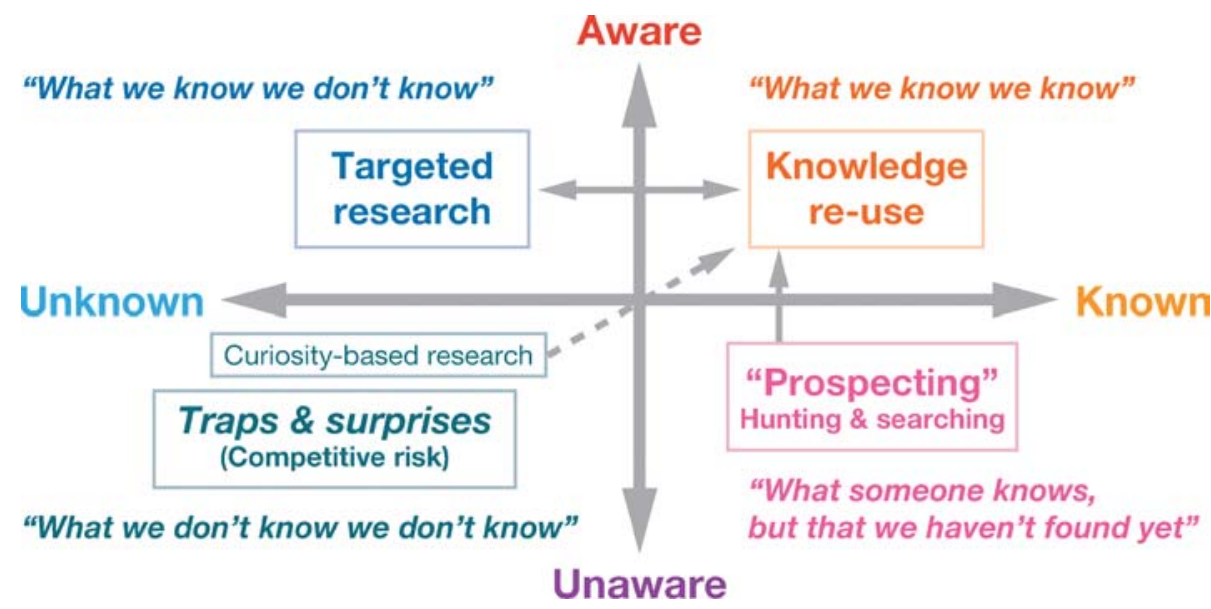

Figure 1

Knowledge Management Space. 
incorporates the desired capabilities. Once technologies that represent a significant advance to a system's capability have been identified, programs of targeted research can be planned and executed. Targeted research programs address technologies of which we are aware, but which are beyond the present state of the art.

The demise of the Space Shuttle Orbiter Columbia during its reentry from orbit on February 1, 2003 was a graphic reminder of how severe the aerothermodynamic environment is for a vehicle that is traveling at hypersonic speeds and of how fragile the vehicles that fly through these environments can be. Using the technologies of the 1970s, the Space Transportation System had been designed to survive repeated flights through the atmosphere from the earth-to-orbit (ETO) and return. However, early in the launch phase of flight STS-107, a piece (or pieces) of the foam protecting the external tank (ET) broke loose and struck one of the reinforced-carbon-carbon (RCC) panels of the leading edge of the left wing. The Orbiter continued on its launch trajectory, reaching orbit "safely." Neither the extent of the damage to the TPS nor the catastrophic consequences of that damage were known as OV-102, the Columbia, orbited the Earth. Thus, those responsible for determining the response of the vehicle to the severe aerothermodynamic environment had to deal with "unknown unknowns."

Post-flight analysis reported by the Columbia Accident Investigation Board (2003) indicated that the impact of the piece of foam produced a breech in the TPS. It is the first author's belief (based on his analysis of the Shuttle Columbia demise) that a relatively small breech of the TPS provided a path for the hot gases in the entry aerothermodynamic environment to reach the interior of the left wing, creating the ever-expanding damage pattern that ultimately led to the demise of OV-102 (the Columbia) during mission STS-107.

The peak heat-transfer rates of a vehicle entering the earth's atmosphere occur at altitudes where the air behaves as a continuum. Nevertheless, anomalously high temperatures already were being measured by temperature sensors located on the clevis and on the spar behind the RCC panel 9 during the fatal reentry of Columbia on mission STS-107 from the entry interface [EI at 91,441 m (300,000 ft)] to 82,297 m $(270,000 \mathrm{ft})$. The density of the air in this altitude range is relatively low. As a result, the mean-free path, i.e., the distance between collisions of air particles, is relatively large. The ratio of the mean-free path to the characteristic length of the vehicle is known as the Knudsen number, $K n$.

$$
K n=\frac{\lambda}{L_{c b a r}}
$$

Typical trajectories of various spacecraft and the regions of different physical and chemical processes in the shock layer near such vehicles are shown in Figure 2, which is taken from Hirschel (1991). Unlike the aerodynamic and heat-transfer characteristics of conventional aircraft, these problems are characterized for reentry (or for ascending) trajectories by a wide range of Reynolds numbers, extremely high Mach numbers, and, therefore, by high temperatures immediately behind the bow shock wave (up to several tens of thousands of degrees before the temperature associated with thermochemical equilibrium is reached). For that portion of the reentry trajectory 


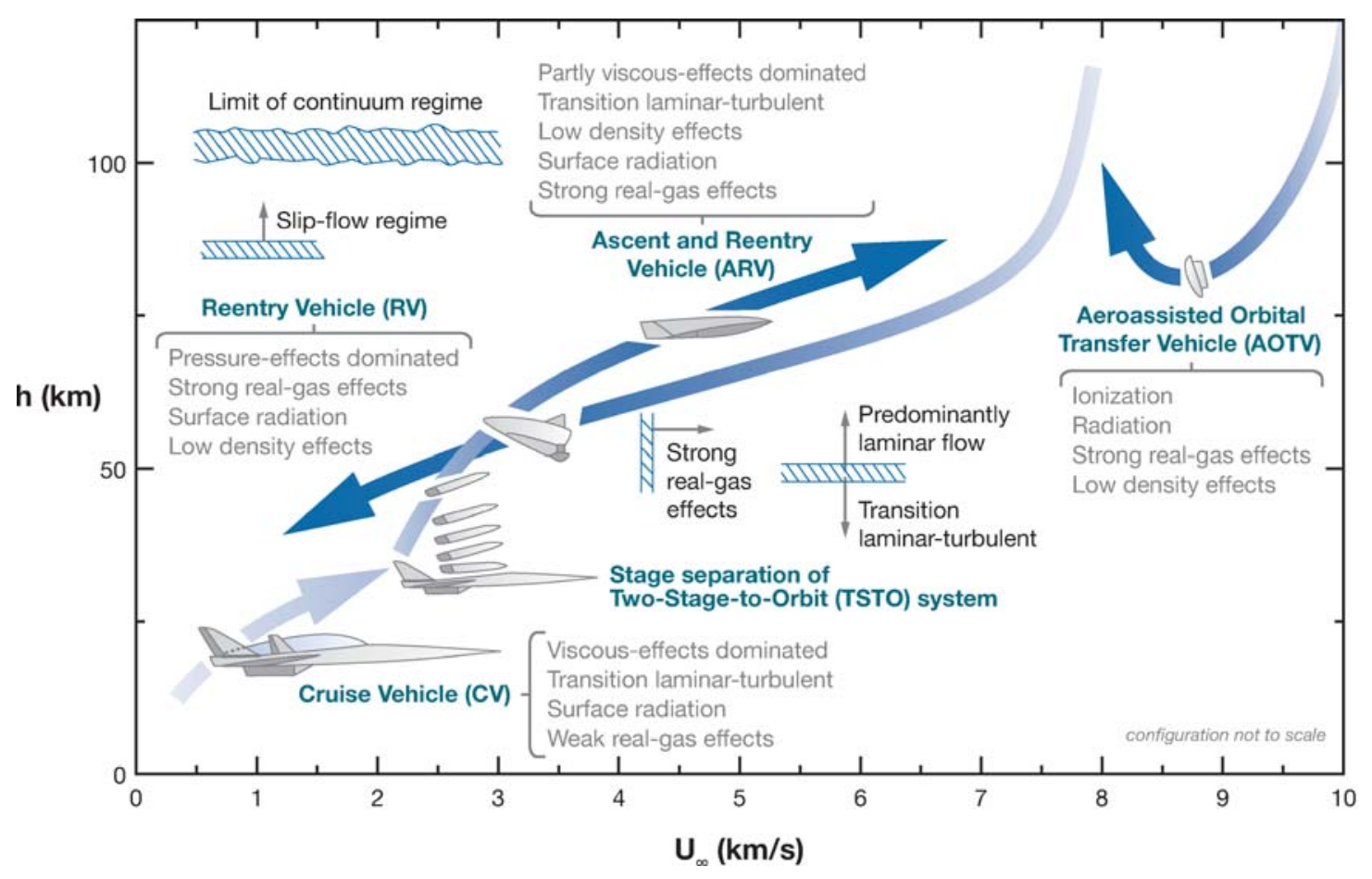

Figure 2

Typical trajectories of various spacecraft.

at altitudes above the continuum flow regime, the stagnation pressure behind the shock wave varies from $10^{-4}$ to $10^{-3}$ atm (Tirsky 1993). LeBeau (1999) states that, "to circumvent the difficulty of a direct solution of the Boltzmann equation, an alternative technique known as the Direct Simulation Monte Carlo (DSMC) was proposed by Bird in 1963. The DSMC method may be regarded as a numerical method for solving the Boltzmann equation." The DSMC Analysis Code (DAC), which (at the time of this writing) represents the National Aeronautics and Space Administration's (NASA's) state-of-the-art implementation of the DSMC method, has been applied to a variety of low-density flows (LeBeau \& Lumpkin 2001).

Because the peak convective heating and the majority of the maneuvering of the vehicle will occur at lower altitudes, where the gas behaves as a continuum, the reader is referred to the substantial literature on the subject of rarefied gas dynamics, e.g., Schaaf (1963), Sherman (1969), Kogan (1973), Bird (1978), Yen (1984), Muntz (1989), Tirsky (1993), and Ivanov \& Gimelshein (1998). These references include seven reviews from the Annual Reviews of Fluid Mechanics. Texts on the subject include that of Bird (1976).

During the late 1960s, NASA and the Air Force were engaged in obtaining flighttest data for a Hypersonic Ramjet Experiment (HRE) that was to be carried to hypersonic velocities on a rocket-powered X-15. As part of the HRE program, a dummy 
model of a ramjet engine was mounted on the ventral fin (or pylon) of the $\mathrm{X}-15$. On May 5, 1967, the X-15A-2 with no ablative coating was flown to a maximum velocity of $1448 \mathrm{~m} / \mathrm{s}(4750 \mathrm{ft} / \mathrm{s})$. The main purpose of this flight was to evaluate the handling qualities of the aircraft with the dummy ramjet installed (Armstrong 1969). Two flights were made with an ablative heat shield protecting the $\mathrm{X}-15 \mathrm{~A}-2$ and with a dummy ramjet engine attached. On the second flight in October 1967, the aircraft achieved a top speed of $2021 \mathrm{~m} / \mathrm{s}(6630 \mathrm{ft} / \mathrm{s})$. Although an ablative heat shield protected the aircraft structure, a shock/shock interaction produced considerable damage to the dummy ramjet and to the ramjet pylon. Gaping holes were burned in the pylon and four probes were lost. Thus, the shock/shock interactions and the viscous/inviscid interactions produced locally severe heating rates that became critical when the vehicle reached Mach 6.7, instead of Mach 4.9 on the previous flights where no damage occurred.

Combinations of Mach number and of angle of attack were determined (Burcham \& Nugent 1970) for which either the shock waves generated by the wing leading edge or by the fuselage side fairing impinged on the pylon/ramjet region. The flow model, which included a separation region and a lambda-shock structure, is similar to those proposed by Westkaemper (1968) and by Stollery (1987). Because of the nearly critical damage to the ramjet engine and to the pylon on which the HRE was mounted, shock/shock interactions became a "known unknown." Extensive research efforts led to the definitive treatise on shock/shock interaction, which was done by Edney. The complete presentation is given in the FFA Report (Edney 1968a). A summary work is more generally available as Edney (1968b).

In another example of an "unknown unknown," Woods et al. (1983) noted that preflight predictions based on the aerodynamics in the Aerodynamic Design Data Book (ADDB) indicated that a $7.5^{\circ}$ deflection of the body flap would be required to trim the Space Shuttle Orbiter for the center of gravity and vehicle configuration of STS-1. In reality, the body flap had to deflect to much larger values $\left(\delta_{B F} \approx 16^{\circ}\right)$ to maintain trim at the proper angle of attack $\left(\alpha=40^{\circ}\right)$. The deflection of $16^{\circ}$ was close to the limit of possible deflections. Comparison of equilibrium-air computations with perfect gas computations indicates that at least part of this so-called hypersonic anomaly was due to real gas effects at very high Mach numbers (Maus et al. 1984).

Finally, an example of a "known unknown" is boundary-layer transition. Vehicles that are powered by air-breathing propulsion systems spend most of their atmospheric hypersonic flight at conditions where the flow will be transitional. Because of this, the importance of understanding and predicting transition will be critical to the design of future hypersonic vehicles. Finding prediction methods that can give results of suitable engineering accuracy for vehicles that contain TPS, relatively complex geometries, varying surface roughness, and various sharp and blunt surfaces will be challenging. Bushnell (1997) has gone so far as to say that, "historically, man has been singularly unsuccessful in 'predicting' transition on essentially everything flown hypersonically (or even supersonically)." Bushnell goes on to use the X-15 as an example, where wind-tunnel data showed that the flow over the vehicle should be mostly laminar, whereas the flight tests showed that the flow was mostly turbulent. The importance of knowing the location of transition during hypersonic flight will 
become increasingly important if advanced vehicles are to be designed that will make hypersonic flight safe, regular, and affordable (Bertin \& Cummings 2003).

This brief introduction underscores the fact that many of the aerothermodynamic phenomena that produce the severe heating rates that place the crew, the vehicle, and/or the mission at risk are only first discovered during fights of vehicles at hypersonic speeds. Furthermore, these locally severe, critical heating rates or unexpected deviations to the forces and moments acting on the vehicle often occur due to viscous/inviscid interactions. These critical environments are the result of "unknown unknowns," or "gotchas." Thus, it is important that those members of the design team who are responsible for determining the aerothermodynamic environment of a new system integrate the various tools into the design process. Thus, one should integrate information from analytical solutions, from the computational fluid dynamics (CFD) efforts, from ground-based test programs, and from flight tests.

\section{TOOLS FOR DEFINING THE CONTINUUM, HYPERSONIC AEROTHERMODYNAMIC ENVIRONMENT}

Those responsible for the definition of the aerothermodynamic environment and the design of the TPS that is required to protect a vehicle flying at hypersonic speeds in that environment have an array of tools available to them. The designer/engineer starts with a mission to design a vehicle that has the appropriate range, payload, and cost. The vehicle is designed to meet certain requirements of operability, maintainability, reliability, safety, etc. From the outset of the design process, the designer/engineer knows that the values of certain "known parameters" that define the aerothermodynamic environment, e.g., the lift, the drag, trim requirements, the TPS, the thermo-chemical state of the gas in the flow field, etc., must be determined. Granted, some of the known parameters have resisted our abilities to determine values whose magnitude can be defined with a reasonable degree of confidence, e.g., determining where boundary layer transition occurs. Nevertheless, we know that we should include them as a factor in the design. Although we remain unable to model rigorously the basic fluid mechanics that governs these parameters, we can estimate their values for the applications of interest. The problems become a crisis for the designer/engineer only when they represent "unknown unknowns." These are phenomena of which the designer/engineer was unaware, when the parameters that needed to be quantified were identified during the design of the vehicle. They create the "gotchas" described earlier in this opus.

\section{Analytical Methods}

Vehicles have been flying at hypersonic speeds since Robert $M$. White flew the North American X-15 at $7274 \mathrm{~km} / \mathrm{h}$ (4520 miles per hour) at 105,218 m (354,200 ft). This remarkable accomplishment of flight at a Mach number of 6.7 occurred more than 40 years ago. In a review of fifty years of technology developments, Bertin \& Cummings (2003) noted that a sustained and visionary effort was needed to generate the required knowledge both through targeted research activities, as well as through 
prospecting. We review the analytical techniques developed 50 years ago by the pioneers of hypersonic flight in this section. Although these techniques were developed long ago and work best for relatively simple shapes, they are of interest to this review because correlations that can be used for extrapolations to the flight environment are of critical interest to today's designers. Furthermore, the simple capsule shapes for which these techniques were developed are candidate concepts for the missions that require superorbital velocities, e.g., return to the moon and planetary exploration. New designs by China and Russia incorporate the capsule concept because they are flexible and simple, and future U.S. crew exploration vehicles may return to the capsule concept. "The shuttles have served the nation well in an era of different spaceflight objectives, payloads, and missions. Now seems to be the time for a blast from the past-simpler and more limited spacecraft that will spark a resurgence in human missions beyond Earth orbit" (Sietzen 2005).

For the windward surface of relatively simple shapes, one can assume that the speed and direction of the gas particles in the free stream remain unchanged until they strike the solid surface exposed to the flow. For this flow model, which is termed Newtonian flow theory because it is similar in character to the one described by Newton in the seventeenth century, the normal component of momentum of an impinging fluid particle is wiped out and the tangential component is conserved. Using the nomenclature of Figure 3, the equation for the local pressure coefficient is:

$$
C_{p}=\frac{p_{s}-p_{\infty}}{0.5 \rho_{\infty} U_{\infty}^{2}}=2 \sin ^{2} \theta_{b}=2 \cos ^{2} \phi
$$

However, because measurements and computations of the stagnation-point value of the pressure coefficient are always less than two, Lees (1955) proposed an alternative representation of the pressure coefficient for hypersonic flow, replacing the factor "2" by the appropriate value of the stagnation-point pressure coefficient at the flow

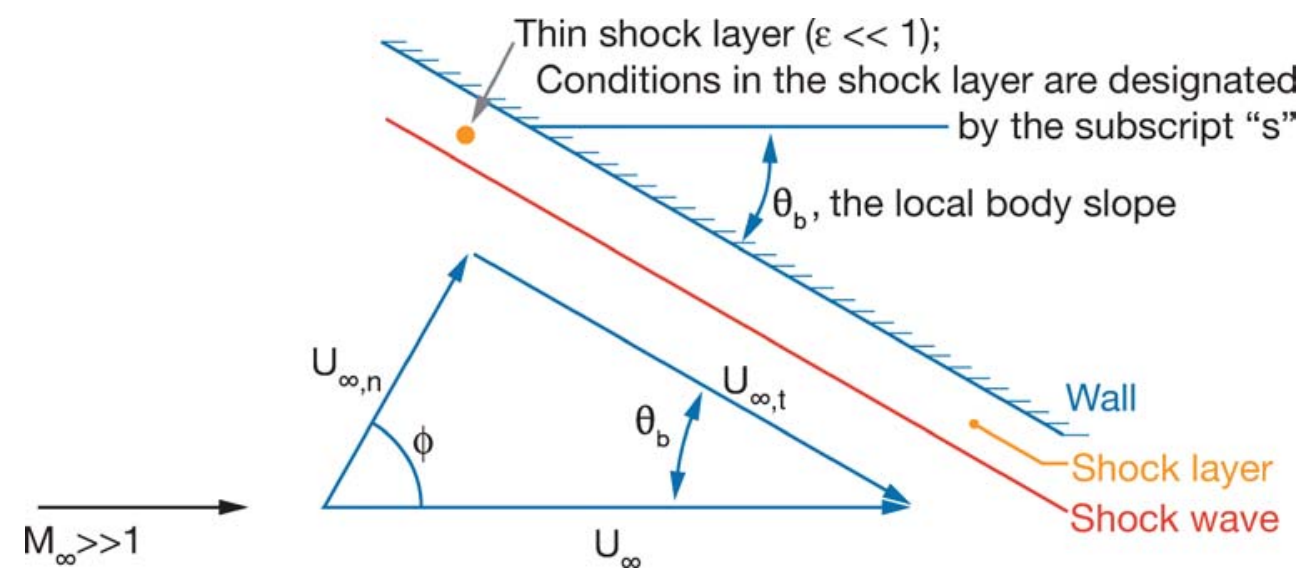

Figure 3

Notation for Newtonian flow theory. 
conditions of interest, which is known as Modified Newtonian flow theory:

$$
C_{p}=C_{p, t 2} \sin ^{2} \theta_{b},
$$

where $C_{p, t 2}$ could be found experimentally or by using the Rayleigh pitot formula. Despite the dramatic improvements in CFD in the 50 years since the introduction of Modified Newtonian flow, the theory continues to be used often to generate engineering approximations for the pressures acting on configurations in hypersonic flows, e.g., Fujimoto et al. (2003), Glass et al. (1989), and Reubush \& Omar (1989).

Many of the early hypersonic vehicles had military applications. Thus, they were high-ballistic coefficient $\left(W / C_{D} A\right)$, low-drag configurations, e.g., slender cones. To keep the stagnation-point heat-transfer rates within acceptable limits, the vehicles usually had a spherical nose cap. The early capsules, which carried astronauts to orbit and beyond, were spherically capped vehicles. Fortunately, the stagnation-point heat transfer for a laminar boundary layer is a problem where a coordinate transformation can be used to reduce the governing partial differential equation for a laminar boundary layer to ordinary differential equations (Fay \& Riddell 1958).

Because the windward surface of the early crewed vehicles, e.g., the Mercury Capsule, the Gemini Capsule, and the Apollo Command Module, consisted of spherical segments, the heating rate to stagnation point of the configuration at zero angle of attack could be calculated using the equations of Fay \& Riddell (1958). Thus, the equations of Fay \& Riddell could be used both to verify the validity of the windtunnel measurements and to produce a parameter that could serve as the denominator of a dimensionless heat-transfer ratio. This dimensionless heat-transfer ratio could then be used to extrapolate the wind tunnel-based measurements to the flight applications. Using a reference stagnation-point heat-transfer rate as the denominator of a dimensionless heat-transfer parameter dates back to the Mercury design, e.g., Weston \& Swanson (1961). The reference stagnation-point heat-transfer rate was for the capsule at zero angle of attack.

However, the spherical segment for each of these capsules is truncated before sonic flow is reached. Thus, the sonic point moves to the edge of the spherical cap, which is upstream of its location if the spherical segment had not been truncated. Because the flow in the shock layer is subsonic, changes to the inviscid flow field propagate throughout the windward shock layer. Thus, in reality, the pressure decreases more rapidly with distance from the stagnation point than would be predicted by the modified Newtonian flow model. The resultant pressure gradient (or, equivalently, the velocity gradient) can be calculated by determining the effective radius of the spherical cap, $R_{\text {eff }}$. See Bertin (1994), Boison \& Curtiss (1959), and Stoney (1958) for more details.

The transformation of the equations of motion from the physical coordinates $(x, y)$ to similarity coordinates $(S, \eta)$ has been discussed at length by Dorrance (1962) and by Hayes \& Probstein (1959). Depending on the specific application, the evolving technology of similarity transformations included contributions by Blasius, Mangler, Howarth, Illingworth, Levy, Dorodnitsyn, and Lees. Lees (1956) developed an equation to determine the heat-transfer rate $(q)$ as a function of distance from the stagnation point for a blunt-nosed body in a hypersonic stream. Lees (1956) 
introduced the limiting approximations for the stagnation-point flow using the same laminar, boundary layer equations with the configuration at zero angle of attack $\left(q_{t, \alpha=0}\right)$. Dividing the similarity-based expression for the heat-transfer distribution for a laminar boundary layer by the stagnation-point heat-transfer rate produces a dimensionless heat-transfer parameter that is a function of the dimensionless thermo properties, e.g., $p_{e} / p_{t 2}$ and $s_{e} / s_{t 2}$, the equivalent cross-sectional radius, or metric (Cooke 1961) and (Hildebrand 1957), and the wetted distance from the stagnation point.

The work by Fay \& Riddell (1958) remains the classic presentation of stagnationregion flow fields for a spherical configuration in a hypersonic stream. Starting from the work of Fay \& Riddell (1958), one can show (Bertin 1994) that an approximate value of the stagnation-point heating rate can be computed using:

$$
\dot{q}_{t, r e f}=\frac{K}{R_{N}^{0.5}}\left(\rho_{1}\right)^{0.5}\left(V_{1}\right)^{3.0} \frac{\left(T_{t 2}\right)^{0.4 E}\left(T_{w}\right)^{0.1 E}}{\left(z_{t 2} T_{t 2}\right)^{0.15}\left(z_{w, t} T_{w}\right)^{0.1}} .
$$

In Equation $4, K$ is the constant to account for units, $R_{N}$ is the nose radius, $\rho_{1}$ is free-stream density, $V_{1}$ is free-stream velocity, $T_{t 2}$ is the total temperature downstream of the shock wave, $T_{w}$ is wall temperature, $Z_{t 2}$ is the compressibility factor at the downstream stagnation point, and $Z_{w, t}$ is the compressibility factor at the wall. Numerous investigators have developed engineering correlations for calculating the convective heat-transfer rate to the stagnation point of a sphere that is flying through a planetary atmosphere (including that of the Earth), e.g., Sutton \& Graves (1971), Scott et al. (1985), and Detra et al. (1957).

The determination of the aerothermodynamic environment of the Space Shuttle Transportation System (STS) in the early 1970s extensively used correlations based on representing the Orbiter by a combination of relatively simple shapes. Although the Shuttle Orbiter flow field contains complexities such as shock/shock interactions and shock/boundary layer interactions, extensive use was made of wind tunnels in determining the aerothermodynamic characteristics of the Shuttle Orbiter, e.g., Romere \& Young (1983), Whitnah \& Hillje (1984), and Surber \& Olsen (1978). Haney (1983) stated that the Space Shuttle Orbiter's TPS was designed mainly on the basis of wind-tunnel data. For the windward (or lower) surface of the Orbiter, the empirical correlations by analytical techniques were developed as follows. As shown in Figure 4a, the Orbiter was divided into a combination of simple shapes, e.g., cones, cylinders, flat plates, spheres, and wedges, for which analytical solutions are available. For example, the wing leading edge was represented by a swept cylinder in order to obtain estimates for the leading-edge heating rates (outside of the shock/shock interaction region). The heating to the windward fuselage was calculated using the standard Eckert-reference-enthalpy flat-plate solutions (Eckert 1955), which are designated "Analytical solution" in Figure 4b. Because the flows over the (elemental) simple shapes are only crude approximations of the actual flows, there are significant differences in the properties at the edge of the boundary layer and in the streamlines, which produce significant differences between the theoretical heat transfer and that measured in the wind tunnel on the Orbiter model. Adjustments, designated "Calibration factor" in Figure $4 b$, were used to take into account such variations as streamline 


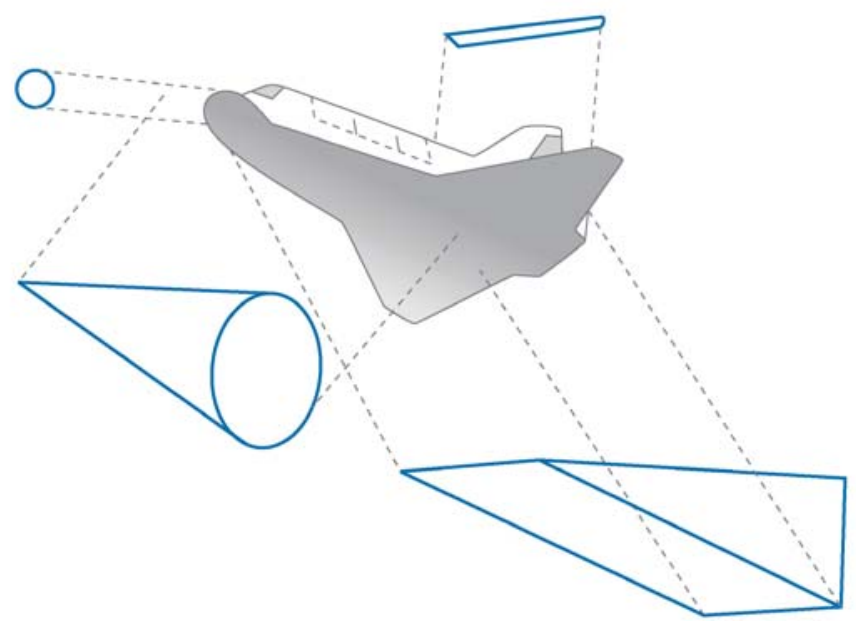

b

Fuselage lower centerline

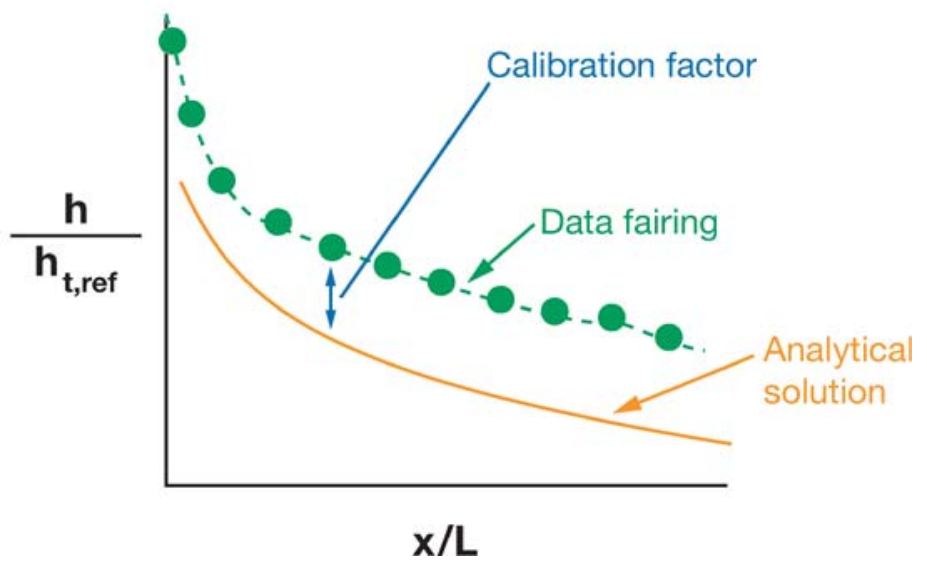

Figure 4

Space Shuttle Orbiter heat-transfer model.

divergence and flow running lengths. When the local value of the heat-transfer parameter from the analytical solutions for the simple geometric shapes is multiplied by the position-dependent calibration factor, one can match the wind-tunnel measurements, designated "Data fairing" in Figure $4 b$. The calibration factors that were developed both for laminar and for turbulent boundary layers were held constant in extrapolations to flight conditions. 
In the early 1960s, researchers from two large organizations developed analytical techniques/experimental facilities for determining the stagnation-point heat-transfer rates at superorbital velocities, i.e., at velocities in excess of $7950 \mathrm{~m} / \mathrm{s}(26,082 \mathrm{ft} / \mathrm{s})$. Buck et al. (1963) noted that there was a controversy at the time regarding the magnitude and the contributing factors causing the increased heating at superorbital velocities. The two dramatically different correlations that were presented in Buck et al. (1963) are reproduced in Figure 5. Because the two groups that developed these correlations contained many competent people, the researchers and their organizations are not identified. Their identity is not important. What is important is that each team of researchers presented both data and theoretical results that were consistent with their position. After extensive analyses of the thermochemistry of the flow, the correlation giving the lower heat-transfer rates was found to be correct.

The objective of this discussion is to point out that the analysis of hypersonic flows involving complex phenomenon should be conducted with considerable thoroughness as well as with competence. One must carefully validate models used to represent physical processes in CFD codes, in addition to evaluating the test conditions and the information of experimental programs. Neumann (1988) correctly noted that, "the codes are NOT an end in themselves ... they represent engineering tools; tools that require engineering to use and critical appraisal to understand. Hypersonics must

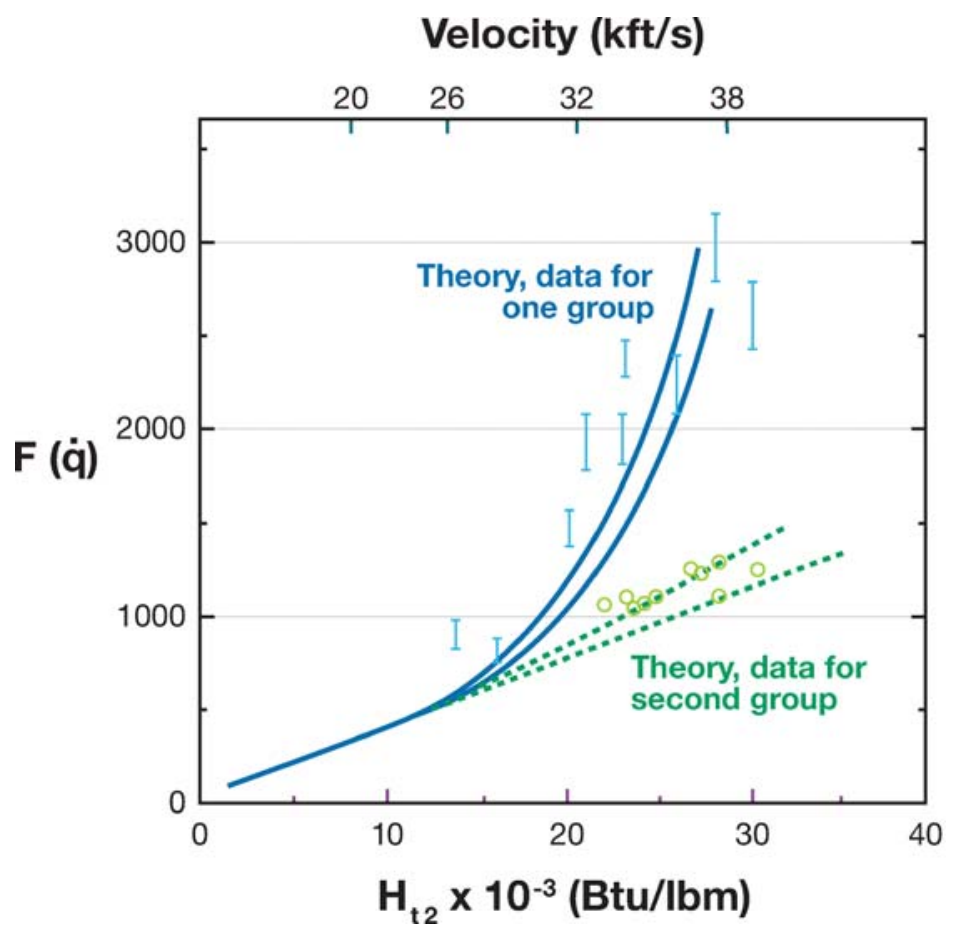

Figure 5

The stagnation-point heat-transfer correlations at superorbital speeds. 
be dominated by an increased understanding of fluid mechanics reality and an appreciation between reality and the modeling of that reality." To correctly simulate hypersonic flows, the flows must be understood and modeled correctly-nowhere is this more true than in the numerical simulation of hypersonic flows. This applies to experiments as well.

\section{Numerical Methods}

A common joke shared among CFD practitioners correctly describes a perceived problem with numerical predictions: "Everyone believes experimental results except the person who performed the experiment, and no one believes numerical results except the person who performed the prediction." No where is this statement more true (and more of a problem) than in hypersonic flow simulation. R.G. Bradley (personal communication) states that, "Although the use of calibrated CFD solutions is dangerous because of the subtle viscous interactions that are extremely sensitive to geometry and flowfield, skilled engineers can often obtain useful design information and guidance from relatively immature codes." With our limited ability to adequately represent hypersonic flow experimentally, the challenge for hypersonic CFD predictions becomes even more difficult because substantial experimental data for a variety of flows and flight conditions are not available.

One only needs to look at the typical assumptions made when deriving the equations of fluid motion to understand why hypersonic flow prediction has been more difficult than lower-speed simulations. Typically, the equations solved in CFD programs are based on the assumptions that the fluid is a continuum, that the perfect-gas law applies, and that the only forces are due to pressure, viscous effects, and body forces. Although the continuum assumption automatically invalidates the equations for rarefied gas flows at high altitudes when the mean-free path of the fluid molecules is on the order of the length of the vehicle, the other assumptions can lead to additional difficulties. These problem areas are due to the complex flow features that can occur in hypersonic flow: thin shock layers (high compression), entropy layers caused by highly swept and curved shock waves, viscous/inviscid interactions, and real gas effects, including dissociation, ionization (high temperatures), and rarefication (high altitudes); see Bertin \& Cummings (2003) for details. Figure 6 shows many of these fluid dynamic challenges in a computation for the Hyper-X vehicle at $M_{\infty}=7$. The thin shock layer coming from the forebody remains very close to the vehicle surface for a large distance down the body length, various shock-shock and shock-boundarylayer interactions occur in the vicinity of the ramp inlet, flow interactions with the engine exhaust and lower surface body contouring create a complex flow field under the back half of the vehicle, and all of this could take place at flight conditions where chemical reactions would be important. This makes for one of CFD's most challenging problems.

Cheng (1993), expanding on the difficulties in predicting viscous/inviscid interations, stated that, "the fluid dynamics of hypersonic flows is complicated by the interaction of the boundary layer and the shear layer with shock waves, leading to flow separation and instability not amenable to straightforward analysis." Many of 


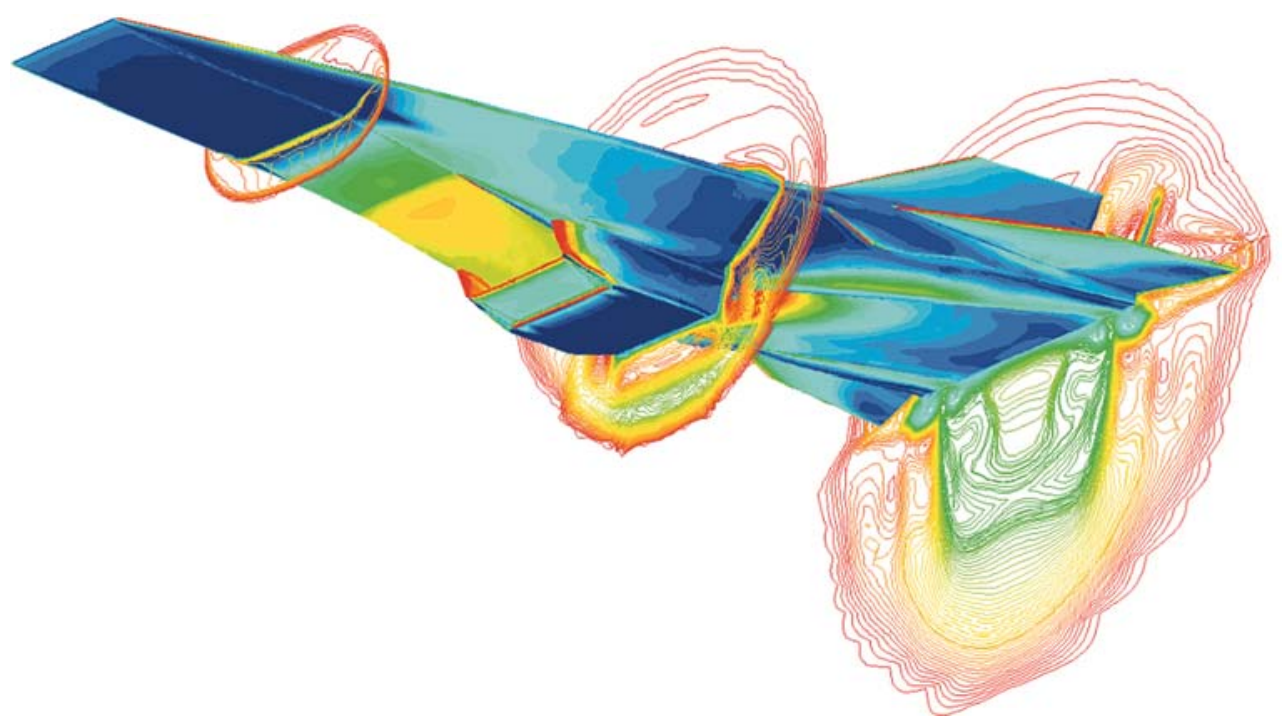

Figure 6

CFD prediction of Hyper-X flow field at $M_{\infty}=7$ with engine operating. (Courtesy of NASA Dryden Flight Research Center).

these flow features tax most computational capabilities, making hypersonic flow a challenging field for CFD. Longo (2003) believes that the key issues for CFD related to hypersonic aerodynamic design, such as real-gas effects, heating, turbulence, and viscous interactions, are currently poorly (or moderately, at best) modeled by CFD. From a simulation perspective, Longo et al. (2000) showed that at least five factors affect the accuracy of flow predictions for re-entry vehicles. These factors include the grid density, the ability to model either equilibrium or nonequilibrium flows, the ability to model transition and turbulence, and the effort involved in accurately modeling the vehicle geometry (especially in regions of shock interactions). They believed that although it is possible for CFD to accurately predict the aerodynamic environment of hypersonic vehicles (including surface pressures and forces/moments), CFD is severely limited in accurately predicting the aerothermodynamic environment of these vehicles. Weiland et al. (2004) add to the list of difficulties with local aerothermodynamic flows (such as flows in deflected flaps and rudders or in gaps between tiles), high-enthalpy flows (including radiation cooling), wall catalycity, turbulence modeling, and jet/airflow interaction. In spite of all these issues, Mehta (1993) believes that CFD will be as important as ground and flight testing in the development of future hypersonic flight vehicles. This leaves a great deal of work to be done to improve computational simulation of high-speed flows.

A variety of important numerical algorithms have been developed over the years specifically to deal with the shocks that are formed at supersonic and hypersonic speeds. Most methods fall into the "shock capturing" approach, where the equations of fluid motion are solved to determine shock locations and strengths. These approaches 
date back to the explicit method of Lax \& Wendroff(1960) and the predictor-corrector scheme of MacCormack (1969). An alternative approach for predicting shocks is "shock fitting" as proposed by Moretti (1974), which uses the Rankine-Hugoniot shock relations to determine shock jump conditions once the position of the shock is known. In spite of the appeal of the shock fitting method, the vast majority of algorithms developed over the years have been of the shock capturing variety.

Shocks cause instabilities in many numerical methods, and must be treated with algorithms that can either deal with the instability through some sort of upwind differencing, or through the explicit addition of numerical smoothing. Unfortunately, the numerical dissipation needed to dampen the shock often degrades the prediction of viscous phenomenon such as boundary layers or vortical flows. Significant improvements in predicting shocks have been made over the years using either the flux vector splitting or flux difference splitting approaches, including Van Leer's second-order extension to Godunov's method (Godunov 1959 and Van Leer 1979), the Steger \& Warming (1981) flux vector splitting approach, Osher \& Solomon's (1982) upwind difference schemes, the implicit upwind scheme of Mulder \& Van Leer (1985), the characteristics-based schemes of Roe (1986), Harten's high-resolution total variation diminishing (TVD) schemes (Harten 1983), Lele's compact finite difference schemes (Lele 1992), and improvements to the advection upstream splitting scheme by Kim et al. (2001a). These advances in computational algorithms, coupled with the amazing development of computer processor speeds (doubling approximately every 18 months according to Moore's Law), have led to improvements in the computational prediction of high-speed flows, but further progress is still needed.

Closely coupled with the numerical algorithm that is being used is the ability to create quality grids during the design and analysis of a vehicle. Grid generation has made great strides over the past decades, with a number of commercially available programs that do a reasonably good job of creating grids around complex geometries, but the difficult requirements of hypersonic flow can tax even the best grid generation software. It can still take weeks or even months to create complex grids, especially if a variety of configurations are being considered during the conceptual design phase. Surface geometry definition and grid generation still remain the biggest bottlenecks in the CFD process. Papadopoulos et al. (1999) stated that, "the factors that limit the use of CFD in the early design phase are how quickly the grids can be generated and how quickly 'sufficiently' accurate CFD simulations can be provided. For complex shapes, 10-100 CFD solutions with marginal fidelity but a very fast turn around time would allow CFD to be part of this stage." In addition, the grid density "support" required in regions of high flow gradients can be difficult to supply, especially without knowing where all of those regions are located a priori. The orientation of the grid relative to a shock can be important, and numerical schemes need to address how to handle shocks with the grid in different orientations to the shock, as discussed by Kim et al. (2001a). Adaptive mesh refinement methods such as that conceived by Pirzadeh (2001) may also prove useful for improving the grid in regions of high flow gradients.

Near the surface of a vehicle, grid resolution can be crucial to the aerothermodynamic predictions being made. Papadopoulos et al. (1999) showed that, "a computational mesh and a level of convergence which result in accurate surface-pressure 
and shear stress values do not guarantee accurate heat-transfer values." In addition, they found that both the level of convergence required for accurate predictions and the numerical algorithm used (including the flux-splitting method and the limiter used) could impact the results of a flow simulation at hypersonic speeds. Papadopoulos et al. (1999) believe that accurate predictions require careful monitoring of both the cell Reynolds number and the temperature jump near the wall. The cell Reynolds number, given by

$$
\operatorname{Re}_{\text {cell }}=\frac{\rho_{\text {wall }} a_{\text {wall }} \Delta y}{\mu_{\text {wall }}}
$$

helps to insure that the initial grid spacing near the wall is small enough to accurately deal with the viscous and heat-transfer effects at the surface. In Equation 5, $\operatorname{Re}_{\text {cell }}$ is the cell Reynolds number, $\rho_{\text {wall }}$ is the density at the wall, $\alpha_{\text {wall }}$ is the speed of sound at the wall, $\Delta y$ is the $y$-step size of the cell, and $\mu_{\text {wall }}$ is the viscosity at the wall. Men'shov \& Nakamura (2000) found that a grid sensitivity study was especially important for accurate flow prediction at hypersonic speeds, and that the cell Reynolds number was especially important to the results: "even a small value of order 10 of $\operatorname{Re}_{\text {cell }}$ might result in $100 \%$ error in the vicinity of the stagnation point, and the heat flux converges when the value of $\mathrm{Re}_{\text {cell }}$ is less than or equal to 3."

The accurate prediction of transition and turbulence is another crucial area in hypersonic flow simulation, but accurate transition models may not be available for a long time due to the difficulties in understanding the transition process in hypersonic flow (Schneider 2004). Although numerical predictions of transition in high-speed boundary layers have been conducted (see Fasel et al. 1993 for example), it remains a daunting challenge to the analyst. Follow the Supplemental Material link from the Annual Reviews home page at http://www.annualreviews.org for a discussion of boundary-layer transition; the reader is referred to the myriad of review papers that are available in the open literature, e.g., Schneider $(1999,2004)$. Only turbulence modeling will be reviewed here.

The ultimate goal of CFD would be to perform direct numerical simulation (DNS) for all aerodynamic flows of interest. However, the computer requirements for such a simulation over realistic vehicles at flight Reynolds numbers make DNS impractical for the foreseeable future, although DNS predictions for simplified geometries are being carried out currently (see, for example, Adams 2000 and Martin 2004). Largeeddy simulation (LES) allows for the modeling of the small scales of turbulence while resolving the large-scale turbulent structures, but is currently limited to low Reynoldsnumber flows (Moin 2002). The most common method for predicting turbulence is the Reynolds-averaged Navier-Stokes (RANS) approach, which requires casting the governing equations with either Reynolds (time) averaging (Reynolds 1895) or Favre (mass-weighted) averaging (Favre 1965).

Over the years, as RANS turbulence models have matured, a plethora of popular new models have been developed that have shown various degrees of success in predicting various flows. Showing particular promise currently are models such as the one-equation model of Spalart \& Allmaras (1992), the $k-\omega$ two-equation model of Wilcox (1988), and the shear-stress transport model of Menter (1994), which combines the $k-\varepsilon$ model of Jones \& Launder (1973) with the $k-\omega$ model of Wilcox. 
One thing is certain: Few, if any, of the models were developed specifically with highspeed flows in mind. Compressible dissipation and pressure dilatation corrections, such as that proposed by Suzen \& Hoffmann (1998), will need to be included to properly model these high-speed flows. Forsythe et al. (2002) showed the impact of compressibility corrections on the prediction of supersonic flows; detailed analysis of these turbulence models and corrections for hypersonic flows are certainly in order.

Showing special promise for predicting turbulent flows are the hybrid RANS/LES turbulence models, such as detached-eddy simulation (DES) by Spalart et al. (1997). The DES model takes advantage of the RANS approach within the attached boundary layer, where RANS models work quite well. Once the flow separates, an LES approach is used, which is computationally affordable with current computers. Again, this approach has shown promise for massively separated flow fields only, including at supersonic speeds as shown by Forsythe et al. (2002), but work is needed to verify that these models work well in hypersonic flows.

Chemically reacting flows take place when the flow-field temperature reaches a level that causes the constitutive parts of the atmosphere to start reacting and changing their basic molecular state. For example, as temperatures reach $2000 \mathrm{~K}$ $(3600 \mathrm{R}) \mathrm{O}_{2}$ begins to dissociate, at $4000 \mathrm{~K}(7200 \mathrm{R}) \mathrm{O}_{2}$ dissociation is complete and $\mathrm{N}_{2}$ dissociation begins, and at $9000 \mathrm{~K}(16,200 \mathrm{R}) \mathrm{N}_{2}$ dissociation is complete and $\mathrm{O}$ and $\mathrm{N}$ begin to ionize (Anderson 1989). Taking these chemical reactions into account is essential to fully analyzing the viscous and heating affects of the flow. According to Edwards (1992), "Several levels of approximation are available to model hypersonic flows. These include the widely-used perfect gas model, along with the more general equilibrium, nonequilibrium, and frozen chemistry assumptions." Cheng \& Emanuel (1995) summarize the difficulty in accurately modeling these chemical reactions: "Current research developments in high-temperature flow physics still do not possess a methodology base with unquestioned certainty. A rational way to derive an equation set for a nonequilibrium flow is to write the time rate of population change of atoms and molecules, with a specific energy state, as the difference between the sum of rates of all collisional and radiative transitions that populate a given state and the sum of rates that depopulate the state." They go on to explain that, "this hypothesis, it should be noted, still requires rather bold assumptions regarding the interaction potentials and the collision mechanisms." In other words, even if we could describe the exact chemical reactions, defining the reaction rates and interactions is something that still requires a fairly high level of modeling.

Perhaps the most commonly used nonequilibrium model in CFD simulations is Park's (1989) two-temperature model. This model uses translational and vibrational temperatures, along with various assumptions about the translational, rotational, vibrational, and electronic excitation modes of the gas species. The impact of using the nonequilibrium model in predicting the flow around an airfoil at hypersonic speeds showed that the lift and pitching moment changed by $10 \%$ and $20 \%$, respectively (Park \& Yoon 1991). Nompelis et al. (2003) found that numerical predictions of heat-transfer rates for a double-cone geometry could differ by $20 \%$ from experimental data, with the nonequilibrium model, the surface no-slip condition, 
grid density, and nonuniform tunnel flow conditions accounting for the difference. Other rate-limiting issues for chemically reacting flows are detailed by Sarma (2000). These include, but are not limited to, the availability of accurate flight-test data for heat fluxes, forces, and moments, the availability of high-fidelity ground-based experimental data with defined and controlled experimental conditions, the applicability of the Navier-Stokes equations and traditional boundary conditions, and non-Boltzmann effects. Sarma concludes that, "it is obvious that we have still a long way to go before fully validated predictive hypersonic CFD codes can emerge out of current efforts" (Sarma 2000). Readers interested in additional details of the difficulties in predicting nonequilibrium flows should refer to the book by Park (1990) on nonequilibrium hypersonic flow and Bird's (1994) book on the direct simulation of gas flows.

The ability to simulate hypersonic flow has not kept stride with the advances made for lower-speed, less-complex flows-it should be apparent that a great deal of work still needs to be done before computational simulations of hypersonic flow are of a caliber that could be used for analysis and design of hypersonic vehicles for the entire flight regime.

\section{Ground-Based Tests}

Despite the remarkable advances in hardware and software for CFD tools, when two critical "return-to-flight" (RTF) concerns were identified in the aerothermodynamic environment of the Space Shuttle, very extensive wind-tunnel programs were conducted. One RTF concern dealt with the heating in the bipod region during launch. The second concern was related to the aerodynamics forces and moments during reentry. Wind-tunnel tests provided the majority of the aerothermal information required by the RTF advisory teams. CFD solutions were used primarily to generate numerical values for use in comparisons with the experimental measurements.

Because there is no single ground-based facility capable of duplicating the hypersonic flight environment, different facilities are used to address various aspects of the design problems associated with hypersonic flight. Most of the measurements that are used during the design process to define the aerothermodynamic environment, i.e., the aerodynamic forces and moments, the surface pressure distribution, and the heat-transfer distribution, are obtained in:

1. conventional wind tunnels,

2. shock-heated wind tunnels,

3. shock tubes,

4. arc-heated test facilities, and

5. ballistic, free-flight ranges.

The parameters that can be simulated in ground-based test facilities include:

1. the free-stream Mach number,

2. the free-stream Reynolds number (and its influence on the character of the boundary layer),

3. the free-stream velocity, 
4. the pressure altitude,

5. the total enthalpy of the flow,

6. the density ratio across the shock wave,

7. the test gas,

8. the wall-to-total temperature ratio, and

9. the thermochemistry of the flow field.

Unfortunately, one cannot simulate all the parameters simultaneously. See the subsequent discussion. Note that some of the parameters are interrelated, e.g., the free-stream velocity, the total enthalpy of the flow, the free-stream Mach number, and the wall-to-total temperature ratio. The critical heating to the bipod region occurs in the Mach number range from 3.5 to 4.0, just prior to staging at approximately $30,480 \mathrm{~m}(100,000 \mathrm{ft})$. Because the total temperature for Mach 4 flow at 30,480 m $(100,000 \mathrm{ft})$ is approximately $950 \mathrm{~K}(1710 \mathrm{R})$, one can simultaneously simulate the free-stream velocity, the total enthalpy of the flow, the free-stream Mach number, and the free-stream Reynolds number in conventional wind-tunnel facilities. Two facilities in which one can match these four parameters are the Supersonic Aerothermal Tunnel $\mathrm{C}$ at the Arnold Engineering Development Center (AEDC) (Anderson \& Matthews 1993) and the LENS II facility at the Calspan-University at Buffalo Research Center (CUBRC) (Holden et al. 1995).

Note also that during a specific run of a wind-tunnel test program, the model temperature usually starts out at room temperature. The temperature measurements that are used to determine the heat-transfer rates to the model are usually made early during the test run. Thus, the temperature of the model surface remains relatively cool during the data-recording portion of the run. On the other hand, the relatively long exposure to the high-temperature flight environment causes the surface of the vehicle to become very hot. As a result, the wall-to-total-temperature ratio in ground-based tests is usually well below the flight value. To match the flight value of the wall-tototal-temperature ratio, the total temperature of the tunnel flow is reduced below the flight value. Thus, even for this relatively benign flow, one does not match the flight values of all of the flowfield parameters.

In addition to the nine flowfield-related parameters that were identified in the second paragraph of this section, additional factors must be considered when developing a test plan. The additional factors include model scale, test time, types of data available, and flow quality (including uniformity, noise, cleanliness, and steadiness).

In a statement attributed to J. Leith Potter, Trimmer et al. (1986) noted that "Aerodynamic modeling is the art of partial simulation." Thus, the test engineer must decide which parameters are critical to accomplishing the objectives of the test program. In fact, during the development of a particular vehicle, the designers will most likely utilize many different facilities with the run schedule, the model, the instrumentation, and the test conditions for each program tailored to answer specific questions. As stated by Matthews et al. (1984), "A precisely defined test objective coupled with comprehensive pretest planning are essential for a successful test program."

There are many reasons for conducting ground-based test programs. They include the following: 
1. Obtain data to define the aerodynamic forces and moments and/or the heattransfer distributions for complete configurations whose complex flow fields resist computational modeling,

2. Use partial configurations to obtain data defining local flow phenomena, such as the inlet flow field for hypersonic air-breathing engines or the shock/boundarylayer interactions associated with deflected control surfaces, such as a body flap.

3. Obtain detailed flow field data to use in developing numerical models for a computational algorithm (code validation).

4. Obtain measurements of parameters, such as the heat transfer and the drag, to use in comparison with computed flow-field solutions over a range of configuration geometries and of flow conditions (code calibration).

5. Obtain data that can be used to develop empirical correlations for phenomena that resist analytical and/or numerical modeling, such as boundary-layer transition and turbulence modeling, and certify the performance of air-breathing engines.

Even today, extensive ground-based test programs are conducted during the design process in order to define the aerothermodynamic environment for the entire vehicle. When the access to space study that was conducted by NASA in the early 1990s recommended the development of a fully reusable launch vehicle (RLV) (Bekey et al. 1994), NASA joined an industry-led technology-development effort for the X33/RLV. As part of the industry/government partnership, personnel and facilities at the Langley Research Center (NASA) were assigned the task of providing information regarding the aerodynamic forces and moments, the surface heating, and the criteria for boundary-layer transition to Lockheed Martin in support of X-33 development and design.

A special section in the September/October 2001 issue of the Fournal of Spacecraft and Rockets presented five archival journal articles documenting the results from this cooperative effort. Two articles, by Horvath et al. (2001) and Murphy et al. (2001), presented information relating to objective 1: "Obtain data to define the aerodynamic forces and moments and/or the heat-transfer distributions for complete configurations whose complex flow fields resist computational modeling." Two articles by Hollis et al. $(2001 \mathrm{a}, \mathrm{b})$ presented information relating to objective 4: "Obtain measurements of parameters, such as the heat transfer and the drag, to be used in comparison with computed flow-field solutions over a range of configuration geometries and of flow conditions (code calibration)." And one article by Berry et al. (2001b) related to objective 5: "Obtain data that can be used to develop empirical correlations for phenomena that resist analytical and/or numerical modeling, such as boundary-layer transition and turbulence modeling."

"In 1996 NASA initiated the Hyper-X program as part of an initiative to mature the technologies associated with hypersonic air-breathing propulsion" (Engelund 2001). "The primary goals of the Hyper-X program are to demonstrate and validate the technologies, the experimental techniques, and the computational methods and tools required to design and develop hypersonic aircraft with airframe-integrated, dualmode scramjet propulsion systems." Although hypersonic air-breathing propulsion systems have been studied in the laboratory environment for more than 40 years, 
a complete airframe-integrated vehicle configuration had never been flight tested. Again, personnel and facilities at the Langley Research Center (NASA) were used to define the aerodynamic and surface heating environments, including information relating to the boundary-layer transition criteria, as part of the design, the development, the construction, and the flight-test program, for the X-43.

A special section in the November/December 2001 issue of the Fournal of Spacecraft and Rockets presented seven archival journal articles summarizing the results from this program. Three articles, by Engelund et al. (2001), Holland et al. (2001), and Huebner et al. (2001), presented information relating to objective 1 .

As described by Woods et al. (2001), the Hyper-X Research Vehicle (HXRV, or free flyer) required a booster to deliver the vehicle to the engine test points. The test conditions for the first flight included $M_{\infty}=7, q_{\infty}=47,879 \mathrm{~N} / \mathrm{m}^{2}(1000 p s f)$ at an altitude of approximately 28,956 m (95,000 ft). The Hyper-X Launch Vehicle (HXLV) stack was initially carried aloft under the wing of a B-52. The HXLV was dropped, the Pegasus ignited, and the stack accelerated to the desired test Mach number. When the stack reached the desired test conditions and attitude, a stage-separation sequence of events separated the free flyer from the booster. The free-flying research vehicle follows a preprogrammed trajectory. Although occurring in less than $500 \mathrm{~ms}$, stage separation is critical to reaching the engine test point and, hence, critical to mission success.

Because of its size and of its long history of store-separation tests at hypersonic speeds with a Captive Trajectory Systems (CTS), Tunnel B at the von Karman Gas Dynamics Facility (VKF) at Arnold Air Force Base in Tennessee became the primary test facility for studying stage separation. The maximum model scale for the Mach 6 tests in Tunnel B was 0.0833. Smaller facilities, specifically the Langley $0.508-\mathrm{m}$ (20-inch) Mach 6 Wind Tunnel and the 0.787-m (31-inch) Mach 10 Wind Tunnel, were initially excluded from stage-separation tests, because their relatively small size could not accommodate a free flyer and the full-length booster at a scale large enough to house force and moment balances. Because Tunnel B is capable of continuous operation for hours, balance heating became an issue that needed additional clarification. The two, smaller Langley facilities became indispensable in addressing concerns that could not be addressed in Tunnel B, including the effects of high heating to the free-flyer balance and blade support interference on free-flyer aerodynamics. The use of three tunnels for the wind-tunnel test program for risk reduction of the stage-separation event demonstrates that: "A precisely defined test objective coupled with comprehensive pretest planning are essential for a successful test program." (Matthews et al. 1984).

Buning et al. (2001) reported that: "Even following the AEDC test, several aerodynamic issues remained in fully understanding the dynamics of the stage-separation maneuver. This understanding was complicated by the unsteady nature of the event, the number of degrees of freedom associated with the booster, research vehicle, and control surfaces; and limits in the amount of wind-tunnel data available. These issues were in three basic areas: unsteady effects, aerodynamic database extrapolation, and differences between wind-tunnel and flight conditions." Viscous and inviscid CFD techniques were used to quantify unsteady effects, to examine the cause and the extent 
of interference between the booster and the research vehicle, and to identify differences between the wind-tunnel and the flight environments.

\section{Flight Tests}

Flight tests are very expensive. Flight tests take a long time to plan and to execute successfully. Furthermore, it is difficult to obtain quality data at well-defined test conditions. Flight tests will never replace ground-based tests or CFD in the design process. Nevertheless, flight tests are critical to our understanding of the hypersonic aerothermodynamic environment because they provide data that cannot be obtained elsewhere.

Neumann (1989) suggests that there are a variety of reasons for conducting flight tests. Four reasons that were suggested by Buck et al. (1963) are:

1. To demonstrate interactive technologies and to identify unanticipated problems;

2. To form a catalyst (or a focus) for technology;

3. To gain knowledge not only from the flights but also from the process of development; and

4. To demonstrate technology in flight so that it is credible for larger-scale applications.

Neumann added three reasons of his own:

5. To verify ground-test data and/or to understand the bridge between ground-test simulations and actual flight;

6. To validate the overall performance of the system; and

7. To generate information not available on the ground.

Williamson (1992) noted: "Due to the large investment in flight testing, it is then desirable to make as many measurements as possible during the flight to help verify predictions or explain any modeling inaccuracies. The instrumentation should measure as directly as possible the things that have been predicted. This is often not possible and it is often necessary to infer predictions from related but not direct measurements." Neumann (1989) stated: "Heat transfer is a quantity which cannot be directly measured: It is interpreted within the context of a thermal model rather than measured." Thus, one must be able to develop a numerical model that describes the relation between the measured temperature and the sensors design in order to obtain a reasonably accurate value of the experimentally determined heat transfer. However, one must also develop a numerical model depicting how the heat-transfer sensor responds from its location in the vehicle. Serious problems can occur when the heat sensor is not properly integrated into the flight structure such that minimal thermal distortion is produced.

Williamson (1992) notes that: "Measurements fall into three groups. These include atmospheric properties measurements, offboard vehicle related sensor measurements, and onboard vehicle related measurements telemetered to the ground or stored on tape and retrieved postflight."

There are two types of flight-test programs: (1) Research \& Development (R \& D) programs and (2) flights of prototype or operational vehicles. R \& D programs 
are focused on technical issues, which drive the design of the vehicle and its flight operations. For example, Project Fire provided calorimeter heating measurements on a large-scale blunt body entering the earth's atmosphere at an initial velocity $11.35 \mathrm{~km} / \mathrm{s}$ $(37.24 \mathrm{kft} / \mathrm{s})$. As discussed by Cornette (1966), the forebody of the "Apollo-like" reentry capsule was constructed of three beryllium calorimeter shields, which were alternated with phenolic-asbestos heat shields. This multiple-layer arrangement provided three distinct time periods when measurements defining the aerothermodynamic environment could be obtained.

Flight-test data have been obtained on prototype vehicles, e.g., the flights of the unmanned Apollo Command Modules, 017 and 020, as discussed in Lee \& Goodrich (1972), and on operational vehicles, e.g., the Space Shuttle Orbiter (Bertin 1994, Bertin et al. 1996). Throckmorton (1992) noted that the concept of using the Shuttle Orbiter as a flight research vehicle, as an adjunct to its normal operational mission, was a topic of discussion within the research community throughout the 1970s. Aerothermodynamic parameters based on flight-test data obtained from thermocouples embedded in the Space Shuttle TPS were used to expand the flight envelope for the Orbiter. Hodge \& Audley (1983) note that:

\footnotetext{
"Requirements for the technique include an analytical model for the simulation of the heat transfer to a point on the TPS, flight test maneuvers which cause the thermocouples imbedded near the surface of the TPS to respond sufficiently above the noise levels, and a parameter estimation program to reduce flight thermocouple data... The data reduction program correlates heating with the variables such as angle of attack, sideslip, control surface deflection, and Reynolds number. This technique could also be used for wind tunnel data reduction."
}

The interactions between impinging shock waves and the bow shock wave can produce locally severe heat-transfer rates. Edney (1968b) identified six different shock/shock interaction patterns. The positive deflection of the Orbiter body flap creates a shock wave, which interacts with the boundary layer on the Orbiter. The adverse pressure gradient produced by the shock wave causes the boundary layer to thicken and, in many cases, to separate. The upstream extent of the interactionproduced perturbations depends on the size of the subsonic portion of the approach boundary layer and on the strength of the shock wave produced by the turning of the flow. Thus, as noted by Bertin (1994), the parameters that influence the extent of an interaction are (1) whether the approach boundary layer is laminar or turbulent, (2) the Mach number of the approach flow, (3) the Reynolds number of the approach flow, (4) the surface temperature, (5) the deflection angle of the ramp, and (6) the chemical state of the gas. Bertin et al. (1996) and Fujii et al. (2001) investigated the perturbed flow fields due to deflected control surfaces using the experimental values of the heat transfer measured during hypersonic flight. The HYFLEX vehicle (Fujii et al. 2001) was a small-scale $R \& D$ vehicle, whose length was $4.40 \mathrm{~m}(14.44 \mathrm{ft})$. A two-stage launcher provided initial altitude of $107 \mathrm{~km}(351 \mathrm{kft})$ at a velocity of $3.88 \mathrm{~km} / \mathrm{s}(12.73 \mathrm{kft} / \mathrm{s})$.

Despite the oft-mentioned problems with developing boundary-layer transition correlations using flight-test measurements, there are numerous flight-test programs 
where boundary-layer transition was a major focus of the data-gathering efforts. Weston \& Fitzkee (1963) noted that observed boundary-layer transition Reynolds numbers on the Mercury capsule "agree well with Reynolds numbers obtained for wake transition Reynolds behind spheres flown in a hypervelocity gun facility." Also flown in the 1960s was the Reentry F vehicle, which provided hypersonic boundarylayer transition, which is still used today. The Reentry F flight provided boundarylayer transition data at Mach numbers up to 20 and altitudes down to $24.38 \mathrm{~km}$ (80.00 kft) (Wright \& Zoby 1977).

\section{CONCLUSIONS}

In spite of the decades of research into hypersonic flow, there are still many challenges to analyzing and designing high-speed vehicles. Recent events such as the Columbia accident are clear evidence that there are still "unknown unknowns" in the field of hypersonic flight that even our best experimental or numerical analysis cannot adequately predict. The inability of hypersonic wind tunnels to simulate adequately the Mach number, Reynolds number, and high-enthalpy states of flight vehicles leave us to approximate and extrapolate our test data. Uncertainty in our ability to model chemical reactions in computational simulations, as well as adequately predict flow features such as shock-shock interactions, leave additional work to be done before CFD predictions of hypersonic flows will be fully trustworthy. Flight testing remains expensive and dangerous and challenges our will to expend resources for discovering the unknown. Understanding hypersonic flow has been challenging researchers for a long time, and will undoubtedly be challenging us for a long time to come.

\section{LITERATURE CITED}

Adams NA. 2000. Direct simulation of the turbulent boundary layer along a compression ramp at $M=3$ and $\operatorname{Re}_{\theta}=1685$. F. Fluid Mech. 420:47-83

Anderson A, Matthews RK. 1993. Aerodynamic and aerothermal facilities. I. Hypersonic wind tunnels. In Methodology of Hypersonic Testing Conf. Belgium: Von Karman Inst.

Anderson JD. 1989. Hypersonic and High Temperature Gas Dynamics. New York: McGraw-Hill

Armstrong JG. 1969. Flight planning and conduct of the X-15A-2 envelope expansion program. Air Force Flight Test Cent. FTC-TD-69-4, Edwards, CA

Bekey I, Powell R, Austin R. 1994. NASA studies access to space. Aerosp. Am. 32:3843

Berry SA, Auslender AH, Dilley AD, Calleja JF. 2001a. Hypersonic boundary-layer trip development for Hyper-X. 7. Spacecr. Rocket. 38:853-64

Berry SA, Horvath TJ, Hollis BR, Thompson RA, Hamilton HH. 2001b. X-33 hypersonic boundary-layer transition. F. Spacecr. Rockets 38:646-57

Bertin JJ. 1994. Hypersonic Aerothermodynamics. Washington, DC: AIAA

Bertin JJ, Bouslog SA, Wang KC, Campbell CH. 1996. Recent aerothermodynamic flight measurements during Shuttle Orbiter re-entry. F. Spacecr. Rockets 33:45762 
Bertin JJ, Cummings RM. 2003. Fifty years of hypersonics: where we've been, where we're going. Progr. Aerosp. Sci. 39:511-36

Bird GA. 1976. Molecular Gas Dynamics. Oxford: Clarendon

Bird GA. 1978. Monte Carlo simulation of gas flows. Annu. Rev. Fluid Mech. 10:11-31

Bird GA. 1994. Molecular Gas Dynamics and the Direct Simulation of Gas Flows. New York: Oxford Univ. Press

Boison JC, Curtiss HA. 1959. An experimental investigation of blunt body stagnation point velocity gradient. ARS 7. 29:130-35

Buck ML, Benson BR, Sieron TR, Neumann RD. 1963. Aerodynamic and performance analyses of a superorbital re-entry vehicle. In Dynamics of Manned Lifting Planetary Entry, ed. SM Scala, AC Harrison, M Rogers, pp. 376-407. New York: Wiley

Buning PG, Wong T-C, Dilley AD, Pao JL. 2001. Computational fluid dynamics prediction of Hyper-X stage separation aerodynamics. F. Spacecr. Rockets 38:82027

Burcham FW, Nugent J. 1970. Local flow field around a pylon-mounted dummy ramjet engine on the X-15-2 airplane for Mach numbers from 2.0 to 6.7. NASA Tech. Note D-5638

Bushnell DM. 1997. Hypersonic flight experimentation—status and shortfalls. Presented at AGARD Interpanel Symp. Future Aerospace Technol. Serv. Alliance, AGARD CP-6000, Paris

Cheng HK. 1993. Perspectives on hypersonic viscous flow research. Annu. Rev. Fluid Mech. 25:455-84

Cheng HK, Emanuel G. 1995. Perspective on hypersonic nonequilibrium flow. AIAA 7. 33:385-400

Cockrell CE, Engelund WC, Bittner RD, Jentink TN, Dilley AD, Frendi A. 2001. Integrated aeropropulsive computational fluid dynamics methodology for the Hyper-X flight experiment. F. Spacecr. Rockets 38:836-43

Columbia Accid. Investig. Board. 2003. Accident Analysis. pp. 49-84. Vol. 1, Ch. 3. Govt. Printing Office

Cooke JC. 1961. An axially symmetric analogue for general three-dimensional boundary layers. Aeronaut. Res. Counc. TR RM 3200. Br. Minist. Aviat., June

Cornette ES. 1966. Forebody temperatures and calorimeter heating rates measured during project Fire II reentry at 11.35 kilometers per second. NASA Tech. Mem. $X-1035$

Detra RW, Kemp NH, Riddell FR. 1957. Addendum to heat transfer to satellite vehicles reentering the atmosphere. Fet Propuls. 27:1256-57

Dorrance WH. 1962. Viscous Hypersonic Flow. New York: McGraw-Hill

Eckert ERG. 1955. Engineering relations for friction and heat transfer to surfaces in high velocity flow. 7. Aeronaut. Sci. 22:585-87

Edney BE. 1968a. Anomalous heat transfer and pressure distributions on blunt bodies at hypersonic speeds in the presence of an impinging shock. Flygtek. Foersoeksanstalten (FFA) Rep. 115

Edney BE. 1968b. Effects of shock impingement on the heat transfer around blunt bodies. AIAA F. 6:15-21 
Edwards TA. 1992. Fluid/chemistry modeling for hypersonic flight analysis. Comput. Math. Appl. 24:25-36

Engelund WC. 2001. Hyper-X aerodynamics: the X-43A airframe-integrated Scramjet propulsion flight-test experiments. F. Spacecr. Rockets 38:801-2

Engelund WC, Holland SD, Cockrell CE, Bittner RD. 2001. Aerodynamic database development for the Hyper-X airframe-integrated scramjet propulsion experiments. F. Spacecr. Rockets 38:803-10

Fasel H, Thumm A, Bestel H. 1993. Direct numerical simulation of transition in supersonic boundary layer: oblique breakdown. In Transitional and Turbulent Compressible Flows, ed. LD Kral, TA Zang, pp. 77-92. New York: ASME

Favre A. 1965. Equations des gaz turbulents compressibles. F. Mec. 4:361-90

Fay JA, Riddell FR. 1958. Theory of stagnation point heat transfer in dissociated air. 7. Aeronaut. Sci. 25:73-85, 121

Forsythe JR, Hoffmann KA, Cummings RM, Squires KD. 2002. Detached-eddy simulation with compressibility corrections applied to a supersonic axisymmetric base flow. F. Fluid. Eng. 124:911-23

Fujii K, Watanabe S, Kurotaki T, Shirozu M. 2001. Aerodynamic heating measurements on nose and elevon of hypersonic flight experiment vehicle. F. Spacecr. Rockets 38:8-14

Fujimoto K, Fujii K, Tsuboi N. 2003. CFD prediction of the aerodynamic characteristics of capsule-like configurations for the future SSTO development. Presented at AIAA Aerosp. Sci. Meet., 41st, AIAA Pap. 03-0912, Reno, NV

Glass DE, Holden MS, Wieting AR. 1989. Effect of leading edge sweep on shock/shock interference at Mach 8. Presented at AIAA Aerosp. Sci. Meet., 27th, AIAA Pap. 89-0271, Reno, NV

Gnoffo PA, Weilmuenster KJ, Hamilton HH, Olynick DR, Venkatapathy E. 1999. Computational aerothermodynamic design issues for hypersonic vehicles. 7. Spacecr. Rockets 36:21-43

Godunov SK. 1959. Finite-difference method for numerical computation of discontinuous solutions of the equations of fluid dynamics. Mat. Sb. 47:271-306

Haney JW. 1983. Orbiter entry heating lessons learned from development flight test program. NASA CP 2283, pp. 719-51

Harten A. 1983. High resolution schemes for hyperbolic conservation laws. F. Comput. Phys. 49:357-93

Hayes WD, Probstein RF. 1959. Hypersonic Flow Theory. New York: Academic

Hildebrand FB. 1957. Advanced Calculus for Engineers. Englewood Cliffs, NJ: PrenticeHall

Hirschel EH. 1991. Viscous effects. Proc. Space Course, pp. 12:1-35. MBBFE202/S/PUB/441. Aachen, Germany

Hodge JK, Audley DR. 1983. Aerothermodynamic parameter estimation from shuttle thermocouple data during transient flight test maneuvers. 7. Spacerr. Rockets 23:453-60

Holden M, Chadwick K, Kolly J. 1995. Hypervelocity studies in the LENS facility. Presented at Int. Aerosp. Planes Hyper. Tech. Conf., 6th, AIAA Pap. 95-6040, Chattanooga, TN 
Holland SD, Woods WC, Engelund WC. 2001. Hyper-X research vehicle experimental aerodynamics test program overview. 7. Spacecr. Rockets 38:828-35

Hollis BR, Horvath TJ, Berry SA, Hamilton HH, Thompson RA, Alter SJ. 2001a. X33 computational aeroheating predictions and comparisons with experimental data. F. Spacecr. Rockets 38:658-69

Hollis BR, Thompson RA, Murphy KJ, Nowak RJ, Riley CJ, et al. 2001b. X-33 aerodynamic computations and comparisons with wind-tunnel data. F. Spacecr. Rockets 38:684-91

Horvath TJ, Berry SA, Hollis BR, Liechty DS, Hamilton HH, Merski NR. 2001. X33 experimental aeroheating at Mach 6 using phosphor thermography. F. Spacerr. Rockets 38:634-45

Huebner LD, Rock KE, Ruf EG, Witte DW, Andrews EH. 2001. Hyper-X flight engine ground testing for flight risk reduction. F. Spacecr. Rockets 38:844-52

Ivanov MS, Gimelshein SF. 1998. Computational hypersonic rarefied flows. Annu. Rev. Fluid Mech. 30:469-505

Jones WP, Launder BE. 1973. The calculation of low-Reynolds-number phenomena with a two-equation model of turbulence. Int. F. Heat Mass Trans. 16:1119-30

Kim KH, Kim C, Rho OH. 2001a. Methods for the accurate computations of hypersonic flows: AUSMPW+ scheme. F. Comput. Phys. 174:38-80

Kim KH, Kim C, Rho OH. 2001b. Methods for the accurate computations of hypersonic flows: shock-aligned grid technique. 7. Comput. Phys. 174:81-119

Kogan MN. 1973. Molecular gas dynamics. Annu. Rev. Fluid Mech. 5:383-404

Lax PD, Wendroff B. 1960. Systems of conservation laws. Commun. Pure Appl. Math. $13: 217-37$

LeBeau GJ. 1999. A parallel implementation of the direct simulation Monte Carlo method. Comput. Methods Appl. Mech. Eng. 174:319-37

LeBeau GJ, Lumpkin FE. 2001. Application highlights of the DSMC analysis code (DAC) software for simulating rarefied flows. Comput. Methods Appl. Mech. Eng. 191:595-609

Lee DB, Goodrich WD. 1972. The aerothermodynamic environment of the Apollo command module during suborbital entry. NASA Tech. Note D-6792

Lees L. 1955. Hypersonic flow. Proc. 5th Int. Aero. Conf., Los Angeles, pp. 241-75. New York: Inst. Aeronaut. Sci.

Lees L. 1956. Laminar heat transfer over blunt-nosed bodies at hypersonic flight speeds. Fet Propuls. 26:259-69, 274

Lele SK. 1992. Compact finite difference schemes with spectral-like resolution. 7. Comput. Phys. 103:16-42

Longo JMA, Orlowski M, Brück S. 2000. Consideration on CFD modeling for the design of re-entry vehicles. Aerosp. Sci. Technol. 4:337-45

Longo JMA. 2003. Aerothermodynamics—a critical review at DLR. Aerosp. Sci. Technol. 7:429-38

MacCormack RW. 1969. The effect of viscosity in hypervelocity impact cratering. AIAA Pap. 69-354

Martin MP. 2004. DNS of hypersonic turbulent boundary layers. Presented at AIAA Fluid Dyn. Conf., 34th, AIAA Pap. 2004-2337, Portland, OR 
Matthews RK, Nutt KW, Wannenwetsch GD, Kidd CT, Boudreau AH. 1984. Developments in aerothermal test techniques at the AEDC supersonic-hypersonic wind tunnels. Presented at AIAA Therm. Conf., 20th, AIAA Pap. 84-1803, Williamsburg, VA

Maus JR, Griffith BJ, Szema KY, Best JT. 1984. Hypersonic Mach number and realgas effects on space shuttle aerodynamics. 7. Spacecr. Rockets 21:136-41

Mehta UB. 1993. Aerospace plane design challenge: credible computations. F. Aircr. 30:519-25

Men'shov IS, Nakamura Y. 2000. Numerical simulations and experimental comparison for high-speed nonequilibrium air flows. Fluid Dyn. Res. 27:305-34

Menter FR. 1994. Two-equation eddy-viscosity turbulence models for engineering applications. AIAA f. 32:1598-605

Moin P. 2002. Advances in large eddy simulation methodology for complex flows. Int. F. Heat Fluid Flow 23:710-20

Moretti G. 1974. On the matter of shock fitting. Lect. Notes Phys. 35:287-92

Mulder WA, Van Leer B. 1985. Experiments with implicit upwind methods for the Euler equations. 7. Comput. Phys. 59:232-46

Muntz EP. 1989. Rarefied gas dynamics. Annu. Rev. Fluid Mech. 21:387-417

Murphy KJ, Nowak RJ, Thompson RA, Hollis BR, Prabhu R. 2001. X-33 hypersonic aerodynamic characteristics. 7. Spacecr. Rockets 38:670-83

Neumann RD. 1988. Missions and requirements. Presented at Spec. Course Aerothermodyn. Hypersonic Veh., AGARD Rep. 761, Neuilly sur Seine, Fr.

Neumann RD. 1989. Defining aerothermodynamic methodology. In Hypersonics. Volume I: Defining the Hypersonic Environment, ed. JJ Bertin, R Glowinski, J Periaux. pp. 125-204. Boston: Birkhaeuser

Nompelis I, Candler GV, Holden MS. 2003. Effect of vibrational nonequilibrium on hypersonic double-cone experiments. AIAA F. 41:2162-69

Osher S, Solomon F. 1982. Upwind difference schemes for hyperbolic systems of conservation laws. Math. Comput. 38:339-74

Papadopoulos P, Venkatapathy E, Prabhu D, Loomis MP, Olynick D. 1999. Current grid-generation strategies and future requirements in hypersonic vehicle design, analysis, and testing. Appl. Math. Model 23:705-35

Park C. 1989. Assessment of two-temperature kinetic model for ionizing flow. $\mathcal{F}$. Thermophys. Heat Trans. 3:233-44

Park C. 1990. Nonequilibrium Hypersonic Aerothermodynamics. New York: WileyIntersci.

Park C, Yoon S. 1991. Fully coupled implicit method for thermochemical nonequilibrium air at suborbital flight speeds. F. Spacecr. Rockets 28:31-39

Pirzadeh S. 2001. Vortical flow prediction using an adaptive unstructured grid method. Presented at NATO Res. Technol. Organ. Meet., Loen, Nor.

Reubush DE, Omar ME. 1989. Pressure and heat transfer investigation of a modified NASP baseline configuration at $M=6$. Presented at AIAA Aerosp. Sci. Meet., 27th, AIAA Pap. 89-0246, Reno, NV

Reynolds O. 1895. On the dynamical theory of incompressible viscous fluids and the determination of the criterion. Philos. Trans. R. Soc. Ser. A 186:123-64

Roe PL. 1986. Characteristic-based schemes for the Euler equations. Annu. Rev. Fluid Mech. 18:337-65 
Romere PO, Young JC. 1983. Space shuttle entry longitudinal aerodynamic comparisons of flight 2 with preflight predictions. F. Spacecr. Rockets 20:518-23

Sarma GSR. 2000. Physico-chemical modeling in hypersonic flow simulation. Prog. Aerosp. Sci. 36:281-349

Schaaf SA. 1963. Mechanics of rarefied gases. In Handbuch der Physik, Strömungsmechnik II, ed. S Flügge. pp. 591-624. Berlin: Springer-Verlag

Schneider SP. 2004. Hypersonic laminar-turbulent transition on circular cones and scramjet forebodies. Prog. Aerosp. Sci. 40:1-50

Schneider SP. 1999. Flight data for boundary-layer transition at hypersonic and supersonic speeds. 7. Spacecr. Rockets 36:8-20

Scott CD, Ried RC, Maraia RJ, Li CP, Derry SM. 1985. An AOTV aeroheating and thermal protection study. In Thermal Design of Aeroassisted Orbital Transfer Vebicles, ed. HE Nelson, 96:198-229. New York: AIAA

Sherman FS. 1969. The transition from continuum to molecular flow. Annu. Rev. Fluid Mech. 1:317-40

Sietzen F. 2005. From Mercury to CEV: space capsules reemerge. Aerosp. Am. 43(2):26-33

Spalart PR, Allmaras SR. 1992. A one-equation turbulence model for aerodynamic flows. Presented at AIAA Aerosp. Sci. Meet., 30th, AIAA Pap. 92-0439, Reno, NV

Spalart PR, Jou W-H, Strelets M, Allmaras SR. 1997. Comments on the feasibility of LES for wings, and on a hybrid RANS/LES approach. In Advances in DNS/LES. Columbus: Greydon

Steger JL, Warming RF. 1981. Flux vector splitting of the inviscid gasdynamic equations with application to finite difference methods. F. Comput. Phys. 40:263-93

Stollery JL. 1987. Some aspects of shock-wave boundary-layer interaction relevant to intake flows. In Aerodynamics of Hypersonic Lifting Vehicles, AGARD CP 428

Stoney WE Jr. 1958. Aerodynamic heating on blunt-nose shapes at Mach numbers up to 14. In NACA Conf. High Speed Aerodyn. Ames Aeronaut. Lab., Moffett Field, CA. NACA RM L58E05a

Surber TE, Olsen DC. 1978. Space shuttle orbiter aerodynamic development. $\mathcal{F}$. Spacecr. Rockets 15:40-47

Sutton K, Graves RA. 1971. A general stagnation-point convective heating equation for arbitrary gas mixtures. NASA Tech. Rep. R-376

Suzen YB, Hoffmann KA. 1998. Investigation of supersonic jet exhaust flows by one-and two-equation turbulence models. Presented at AIAA Aerosp. Sci. Meet., 36th, AIAA Pap. 98-0322, Reno, NV

Throckmorton DA. 1992. Shuttle entry aerothermodynamic flight research: the Orbiter experiments program. Presented at AIAA Aerosp. Ground Test. Conf., 17th, AIAA Pap. 92-3987, Nashville, TN

Tirsky GA. 1993. Up-to-date gasdynamic models of hypersonic aerodynamics and heat transfer with real gas properties. Annu. Rev. Fluid Mech. 25:151-81

Trimmer LL, Cary AM, Voisinet RL. 1986. The optimum bypersonic wind tunnel. Presented at Aero. Test. Conf., 14th, AIAA Pap. 86-0739, West Palm Beach, FL

Van Leer B. 1979. Towards the ultimate conservative difference scheme. F. Comput. Phys. 32:101-36 
Weiland C, Longo J, Gülhan A, Decker K. 2004. Aerothermodynamics for reusable launch systems. Aerosp. Sci. Tech. 8:101-10

Westkaemper JC. 1968. Turbulent boundary-layer separation ahead of cylinders. AIAA 7. 6:1352-55

Weston KC, Fitzkee AL. 1963. Afterbody heat transfer measurements obtained during reentry of the spacecraft of the Mercury-Atlas 5 mission. NASA Tech. Mem. $X-564$

Weston KC, Swanson JE. 1961. A compilation of wind-tunnel heat-transfer measurements on the afterbody of the Project Mercury capsule reentry configuration. NASA Tech. Mem. X-495

Whitnah AM, Hillje ER. 1984. Space shuttle wind tunnel testing program summary. NASA Ref. Publ. 1125

Wilcox DC. 1988. Reassessment of the scale determining equation for advanced turbulence models. AIAA F. 26:1299-310

Williamson WE. 1992. Hypersonic flight testing. Presented at AIAA Aerosp. Ground Test. Conf., 17th, AIAA Pap. 92-3989, Nashville, TN

Woods WC, Arrington JP, Hamilton HH. 1983. A review of preflight estimates of real-gas effects on space shuttle aerodynamic characteristics. In Shuttle Performance: Lessons Learned. NASA Conf. Publ. 2283

Woods WC, Holland SD, DiFulvio M. 2001. Hyper-X stage separation wind-tunnel test program. 7. Spacecr. Rockets 38:881-19

Wright RL, Zoby EV. 1977. Flight boundary layer transition measurements on a slender cone at Mach 20. Presented at AIAA Plasma Fluid Dyn. Conf., 10th, AIAA Pap. 77-719, Albuquerque, NM

Yen SM. 1984. Numerical solution of the nonlinear Boltzmann equation for nonequilibrium gas flow problems. Annu. Rev. Fluid Mech. 16:67-97 